
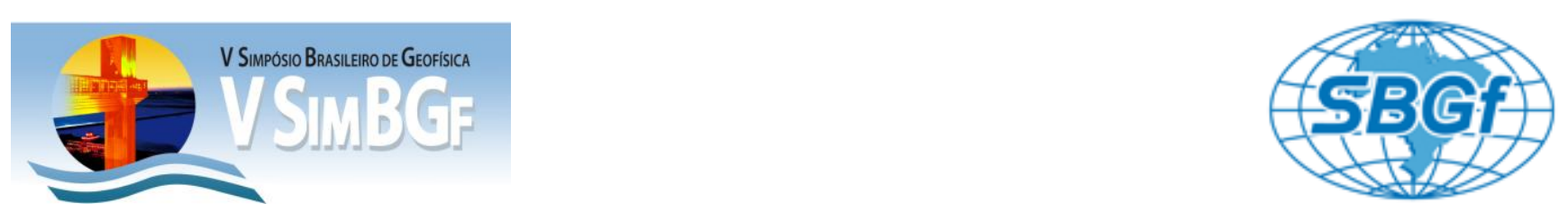

\title{
Investigação geofísica em sítio estuarino no município de Penalva - MA
}

Herson Oliveira da Rocha*, UFPA/CPGf

Marcos Welby Correa Silva, UFPA/CPGf

Fernando Luiz Tavares Marques, Museu Paraense Emílio Goeldi

Deusdédit Carneiro Leite Filho, Instituto Politécnico de Tomar - Portugal.

Copyright 2012, SBGf - Sociedade Brasileira de Geofísica

Este texto foi preparado para a apresentação no V Simpósio Brasileiro de Geofísica, Salvador, 27 a 29 de novembro de 2012. Seu conteúdo foi revisado pelo Comitê Técnico do V SimBGt, mas não necessariamente representa a opinião da SBGf ou de seus associados. É proibida a reprodução total ou parcial deste material para propósitos comerciais sem prévia autorização da SBGf.

\section{Resumo}

Esta pesquisa apresenta os resultados da aplicação de métodos geofísicos não invasivos, visando a indicação de possíveis locais de deposição de materiais, no levantamento arqueológico em um sítio estuarino localizado no município de Penalva, no estado do Maranhão. Os métodos utilizados foram Radar de Penetração no Solo (GPR) e Magnetometria. As medidas magnéticas foram utilizadas para indicar os locais para escavação. O GPR foi utilizado para correlacionar as anomalias geradas pelo método magnético proporcionando a diminuição de erros quando se identificam anomalias magnéticas que não são provenientes de feições arqueológicas. Foram realizados 14 perfis de GPR, utilizando uma antena monoestática de $400 \mathrm{MHz}$. Os resultados apresentados nesta pesquisa permitiram verificar e avaliar a potencialidade da prospecção geofísica como método auxiliar em estudos arqueológicos.

\section{Introdução}

No início do século XIX moradores da baixada maranhense e viajantes que passaram pela região, área de planície fluvio-marinha caracterizada por rios perenes e um mosaico de lagos e campos inundáveis, observaram e descreveram restos construtivos, esteios de diferentes dimensões fixados em "croas", associados a grande quantidade de fragmentos cerâmicos, líticos e restos alimentares, que afloravam nas margens ou nos "tesos" dos lagos nos períodos de estiagem mais prolongadas. Reflexões mais recentes sobre a importância de tais assentamentos apontam à necessidade de estudos locais mais conclusivos. Esses remanescentes de habitações construídas sobre esteios são considerados totalmente originais dentro do quadro atual da arqueologia brasileira (PROUS, 1992).

A aplicação de métodos geofísicos tem se tornado alvo de grande interesse como ferramenta auxiliar à pesquisa arqueológica, com isso possibilita o desenvolvimento de estudos passíveis de análise das dimensões e posições de artefatos arqueológicos, bem como auxiliar na localização de antigas estruturas soterradas, apontando assim, para o local ideal de escavações em sítios arqueológicos, com a vantagem de sua natureza não invasiva para execução desse tipo de trabalho.

Os primeiros trabalhos de prospecção geofísica aplicada na Amazônia que se tem registro foram realizados em 1977 no Sítio Teso dos Bichos, na llha do Marajó (Alves, 1979; Alves \& Lourenço, 1981; Roosevelt, 1991). Recentemente, outros levantamentos foram realizados: na região do Rio Anajás, na llha de Marajó (Barradas et AL., 1999), e em algumas cidades do Pará (Aragão, 2006).

No levantamento arqueológico preliminar antes do levantamento geofísico, a equipe liderada pelo arqueólogo Deusdédit Carneiro Leite Filho, realizaram três escavações (figura 1) preliminares dentro do sítio, o que lhes permitiram o resgate de vários fragmentos cerâmicos.

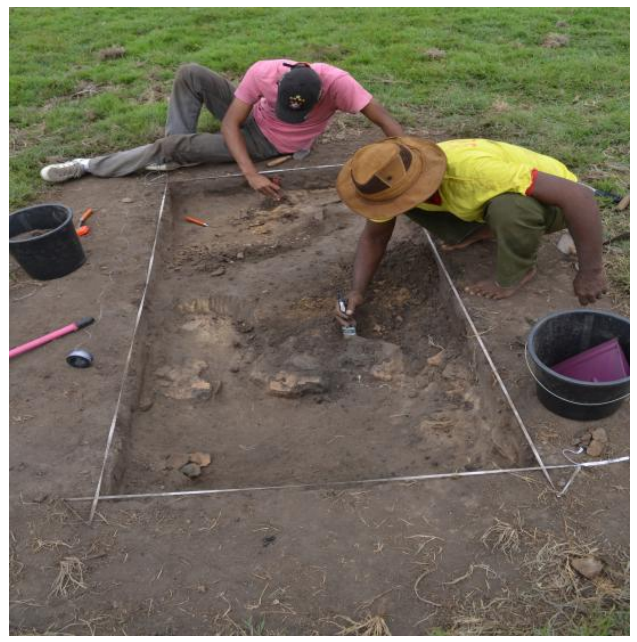

Figura 1- Escavação arqueológica no sítio Lago da Lontra

Neste trabalho é descrito o levantamento geofísico realizado no qual o objetivo é auxiliar a prospecção arqueológica, indicando locais para novas escavações com 0 objetivo de detectar artefatos cerâmicos enterrados no sítio, pois estes normalmente produzem distorções no campo magnético terrestre.

\section{Metodologia/ Problema Investigado}

As medidas magnéticas (figura $2 \mathrm{a}$ ) foram realizadas com magnetômetro de precessão de prótons GEOMETRICS, modelo G-856 AX Memory-Mag, cuja técnica empregada foi o gradiente magnético vertical. Como o sítio têm dimensões de $80 \mathrm{~m}$ na direção $\mathrm{W}-\mathrm{E}$ e $130 \mathrm{~m}$ na direção $\mathrm{S}-\mathrm{N}$, as medidas foram tomadas em intervalos de $2,5 \mathrm{~m}$ 
sobre linhas espaçadas de $80 \mathrm{~m}$ de comprimento e orientadas na direção W-E.

Para as medidas de GPR (figura $2 b$ ) foi utilizada uma antena monoestática de $400 \mathrm{MHz}$ por possibilitar a investigação esperada para os artefatos arqueológicos do sítio estuarino (inferior a $2 \mathrm{~m}$ ), e 0 equipamento TerraSIRch SIR (Subsurface Interface Radar) System3000 fabricado pela GSSI (Geophysical Survey Systems, Inc.),operando em modo tempo e contínuo.

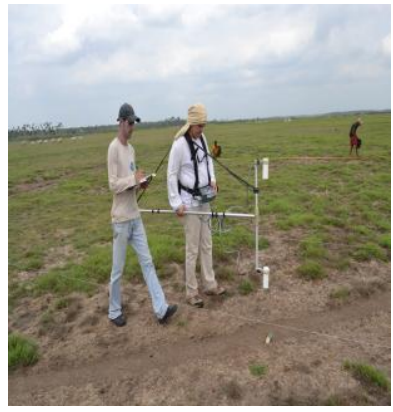

(a)

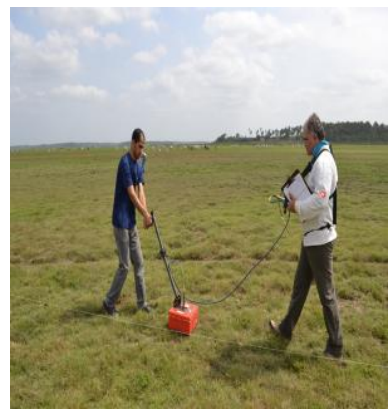

(b)
Levantamento Magnético Levantamento com GPR

O mapa magnético (figura 3 ) mostra o posicionamento dos perfis de GPR executados e a sua relação com as anomalias magnéticas.

O comprimento dos perfis de GPR foi escolhido de modo a cobrir as anomalias evidenciadas no mapa magnético. A investigação foi feita em 14 perfis $\left(P 1, P 2, \ldots, P_{n}\right)$ ao longo das linhas, com marcações a intervalos de $10 \mathrm{~m}$ e janela de tempo de 50 ns para os perfis que estão na direção S-N e 60 ns para os que estão na direção W-E.

Em seguida, foi feita a interpolação das marcas para espaçamento uniforme entre as medidas, correção estática ou ajuste do tempo zero (posição da superfície do terreno), filtros 1-D substract-mean (dewow), filtros 2D runinng average e background removal, determinação da velocidade de propagação da onda eletromagnética usando o método de sobreposição de hipérboles e conversão da escala vertical de tempo em profundidade.

\section{Resultados}

Observa-se no mapa uma série de anomalias variando de $-33 \mathrm{nT}$ a $11 \mathrm{nT}$, que podem estar relacionadas a material cerâmico. Com base na (figura 2) foram sugeridas oito zonas para escavações arqueológicas, marcadas como: $[A],[B],[C],[D],[E],[F],[G]$ e $[H]$. No entanto, por ser um sítio estuarino, no período chuvoso, o mesmo ficou submerso e só foi possível realizar as escavações $[A],[B],[C],[D]$ e $[E]$. As anomalias magnéticas foram confirmadas através de escavações que evidenciaram uma grande quantidade de materiais, tais como: fragmentos de cerâmica, argila queimada e carvão.

$\mathrm{Na}$ análise e interpretação dos radargramas obtidos em cada um dos perfis, procurou-se localizar contrastes de zonas onde há uma descontinuidade no acamamento das camadas, na tentativa de localizar possíveis áreas de descarte de material. Dentre os perfis de GPR realizados,

podemos destacar os perfis $4,7,10,11$, e 13 , os quais apresentaram zonas anômalas relacionadas às anomalias do mapa magnético e serão descritos a seguir.

O perfil 4 estende-se por $30 \mathrm{~m}$ na direção N-S. O radargrama obtido nesse perfil notam-se duas zonas resistivas, a primeira está localizada entre as posições 2 e $8 \mathrm{~m}$ do perfil e a segunda está entre 14 e $15 \mathrm{~m}$. Percebem-se, ainda, um refletor na posição $16 \mathrm{~m}$ do inicio do perfil, causado pela presença de um esteio de madeira e uma anomalia na posição $26 \mathrm{~m}$, que corresponde ao local onde foi detectada uma das anomalias magnéticas [A], cuja escavação (figura 4) evidenciou fragmentos de cerâmica, carvão e um esteio.

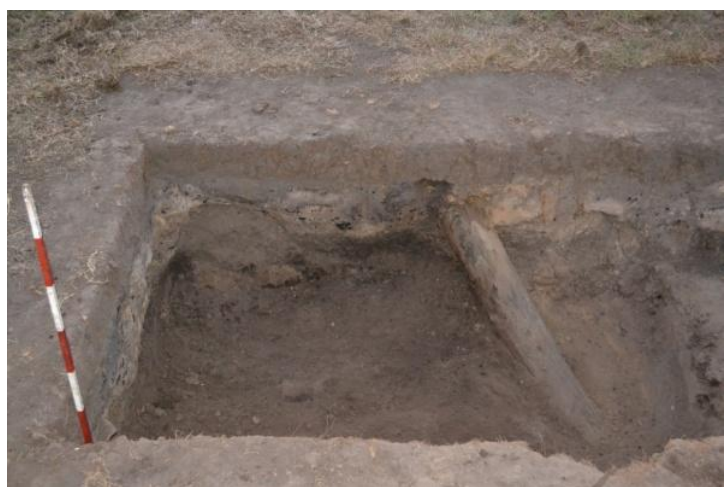

Figura 4 - Escavação arqueológica

O perfil 13 tem direção $W-E$ e possui $80 \mathrm{~m}$ de comprimento, é paralelo ao perfil 12 e semelhante ao perfil 11. O radargrama obtido nesse perfil mostra uma zona resistiva entre a posição 13 e $21 \mathrm{~m}$, bem como uma descontinuidade no acamamento das camadas na posição 33 e $35 \mathrm{~m}$, conforme anomalia [B] vista no mapa magnético e confirmada na escavação (figura 5), evidenciando a presença de carvão e uma fina camada de argila a aproximadamente $20 \mathrm{~cm}$ de profundidade.

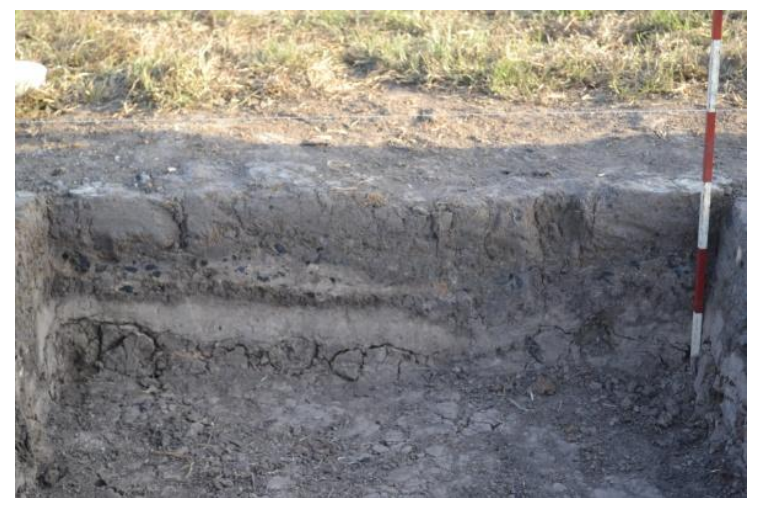

Figura 5 - Escavação arqueológica

A figura 6 mostra a imagem da escavação realizada com base na anomalia magnética [C]. O perfil executado sobre tal anomalia é o 11 que tem direção S-N, mede 80 $\mathrm{m}$ de comprimento e é paralelo ao perfil 10, está localizado na região central do mapa magnético. Observa-se nesse perfil uma zona de descontinuidade no acamamento das camadas entre a posição 28 e $32 \mathrm{~m}$, proveniente de rejeitos das escavações realizadas nesse local. 


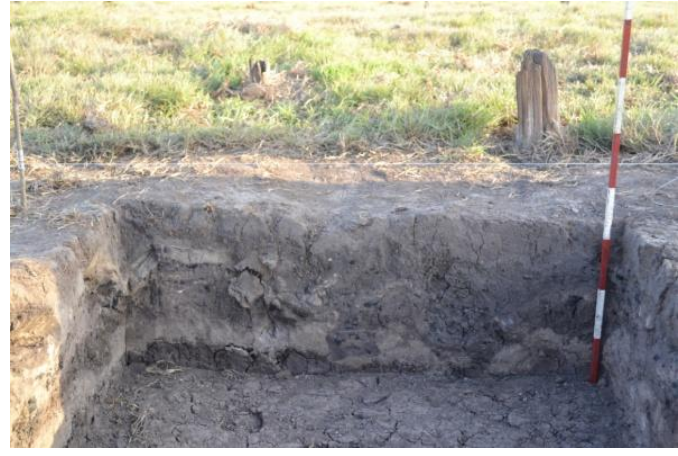

Figura 6 - Escavação arqueológica

O perfil 10 possui $80 \mathrm{~m}$ de comprimento e direção $W$-E, é semelhante ao perfil 9 , distinguindo-se deste por não ser perpendicular ao perfil 1. Observam-se, nesse perfil (figura 7), três zonas anômalas: na primeira zona há uma descontinuidade no acamamento das camadas entre a posição 26 e $36 \mathrm{~m}$, próxima à anomalia magnética [A] com uma profundidade de $0,6 \mathrm{~m}$, bem como uma segunda zona resistiva entre a posição 48 e $62 \mathrm{~m}$ referente à anomalia magnética [D], provocada provavelmente pela presença de argila e no finalmente, outra zona também resistiva entre a posição 66 e $72 \mathrm{~m}$.

$\mathrm{E}$, por fim, o perfil 7 que possui $80 \mathrm{~m}$ de extensão na direção W-E. Esse perfil passa perpendicularmente sobre os perfis $01,02,03,05$ e 06 . O radargrama desse perfil (figura 8) mostrou as seguintes anomalias: Descontinuidades entre 6 e $12 \mathrm{~m}$, podendo está relacionada a anomalia magnética $[E]$, bem como um refletor a uma distância de $32 \mathrm{~m}$ do inicio do perfil, e há, ainda, um arqueamento nas camadas que vai da posição $60 \mathrm{~m}$ até o termino do perfil coincidindo com a anomalia magnética [G].

\section{Discussão e Conclusões}

Os resultados apresentados neste trabalho permitiram verificar e avaliar a correlação entre os dados magnéticos e os perfis de GPR para indicar os possíveis locais de escavações arqueológicas.

As imagens de satélite do sítio não tem uma boa resolução para georeferenciamento, com isso foi utilizado um quadricóptero (figura 9) na tentativa de capturar uma imagem de boa qualidade, mas o mesmo encontrava-se submerso.

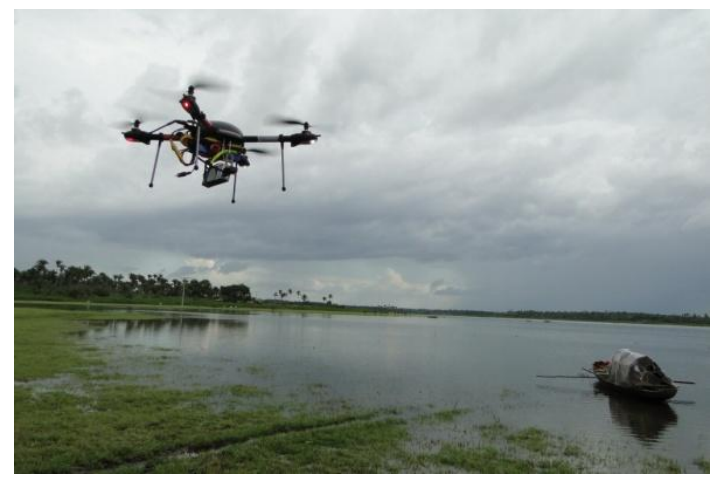

Figura 9 - Quadricóptero sobrevoando o sítio

O método magnético é o mais preciso e mais utilizado, pois proporciona a melhor resposta geofísica, principalmente quando o material arqueológico é constituído de cerâmica, artefatos metálicos e carvão.

O material encontrado encontra-se no Centro de Pesquisa da História Natural e Arqueológica do Maranhão para análise e datação dos povos antigos que habitaram aquela região.

É importante salientar que a resposta geofísica, em alguns casos, é ambígua, por diversos fatores. Daí a cooperação entre geofísicos e arqueólogos na tentativa de minimizar tais ambiguidades na escolha dos locais para escavação arqueológica.

A integração de métodos geofísicos aplicados no Sítio Lago da Lontra foi satisfatória na localização e prospecção de material arqueológico.

\section{Agradecimentos}

O primeiro autor agradece a CAPES pela concessão de bolsa de estudo para o desenvolvimento dessa pesquisa e ao Programa de Pós-Graduação em Geofísica do Instituto de Geociências da UFPA pela estrutura, suporte e logística proporcionada à realização desta pesquisa.

\section{Referências}

Alves, J. J. A., 1979, Métodos Geofísicos Aplicados à Arqueologia no Estado do Pará. Tese de Mestrado em Geofísica. Curso de Pós-Graduação em Ciências Geofísicas e Geológicas. Universidade Federal do Pará, $55 \mathrm{p}$.

Alves e Lourenço, J. S., 1981, Métodos Geofísicos Aplicados à Arqueologia no Estado do Pará, Boletim do Museu Paraense Emílio Goeldi, Série Geologia, 26: 1-52.

Aragão, R. C., 2006, Metodologia geofísica aplicada à pesquisa de salvamento arqueológico nos sítios Bittencourt, Jambuaçu e Jaburu, estado do Pará. Dissertação de Mestrado. Belém: Curso de PósGraduação em Geofísica, Universidade Federal do Pará, 60 p.

Barradas, J. A., Schaan, D. P., and Luiz, J. G., 1999, Magnetic and GPR Survey to Identify Archaeological Features on Cacoal Site, Anajás River, Marajó Island, Pará, Brazil, Resumo Expandido, Sexto Congresso Internacional da SBGf, Rio de Janeiro, RJ, Brasil.

Borges, W. R., 2007. Caracterização Geofísica de alvos rasos com aplicações no planejamento urbano e meio ambiente: estudo sobre o sítio controlado do IAG/USP. Tese de Doutorado (Departamento de Geofísica), IAG/USP, 271p.

Daniels, D.J., 1996. Surface Penetrating Radar. The Institution of Electrical Engineers, London, United Kingdom.

Prous, A. Arqueologia Brasileira. Brasília: Editora UNB, 1992.

Roosevelt, A. C., 1991, Moundbuilders of the Amazon: Geophysical Archaeology on Marajo Island, Brazil, Academic Press, San Diego, 495p.

www.g1.globo.com/ma/maranhao/noticia/2012/05/sitiosarqueologicos-do-maranhao-sao-estudados-porpesquisadores.html. 


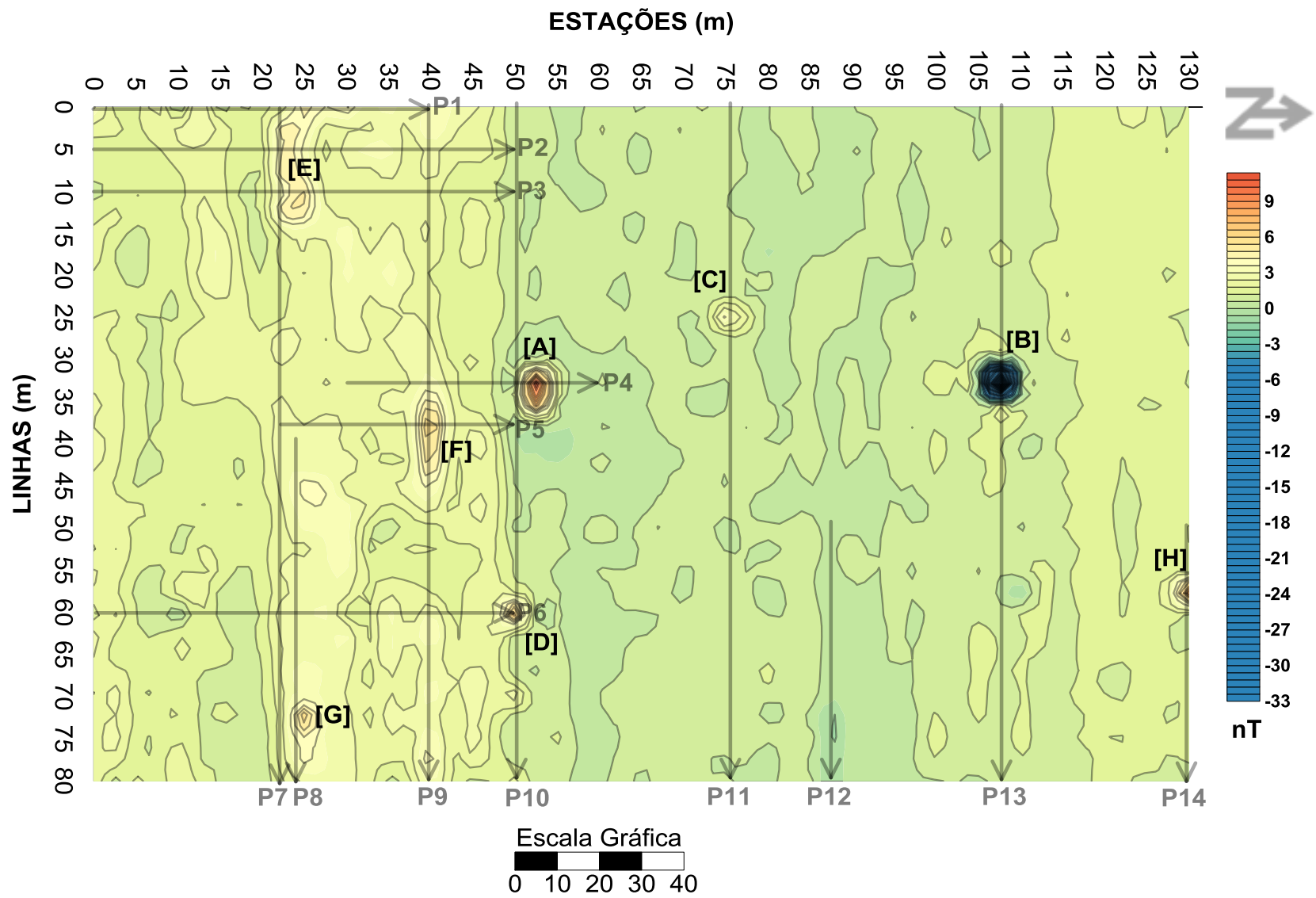

Figura 3- Mapa magnético e posicionamento dos perfis de GPR

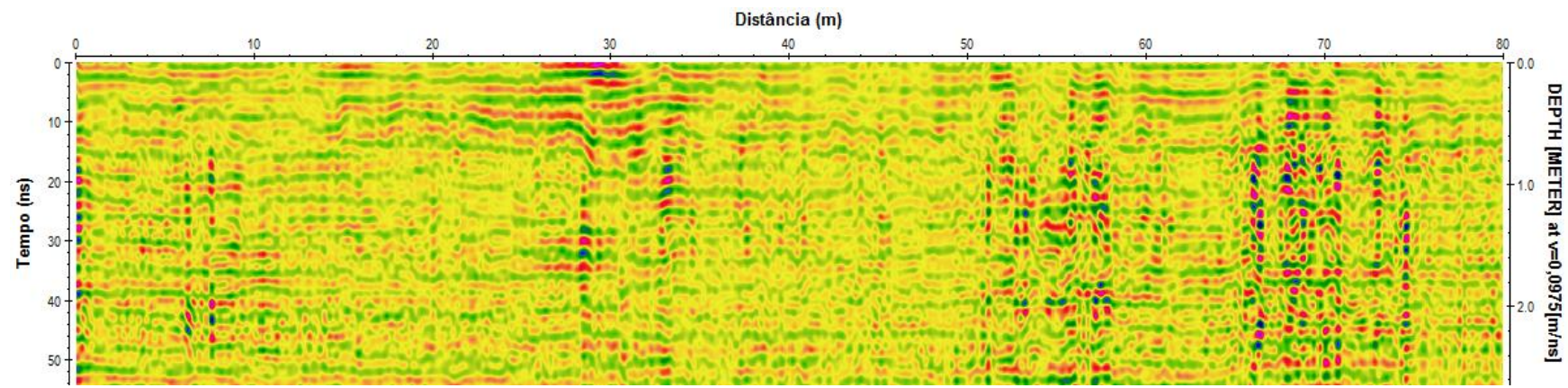

Figura 7 - Perfil 10

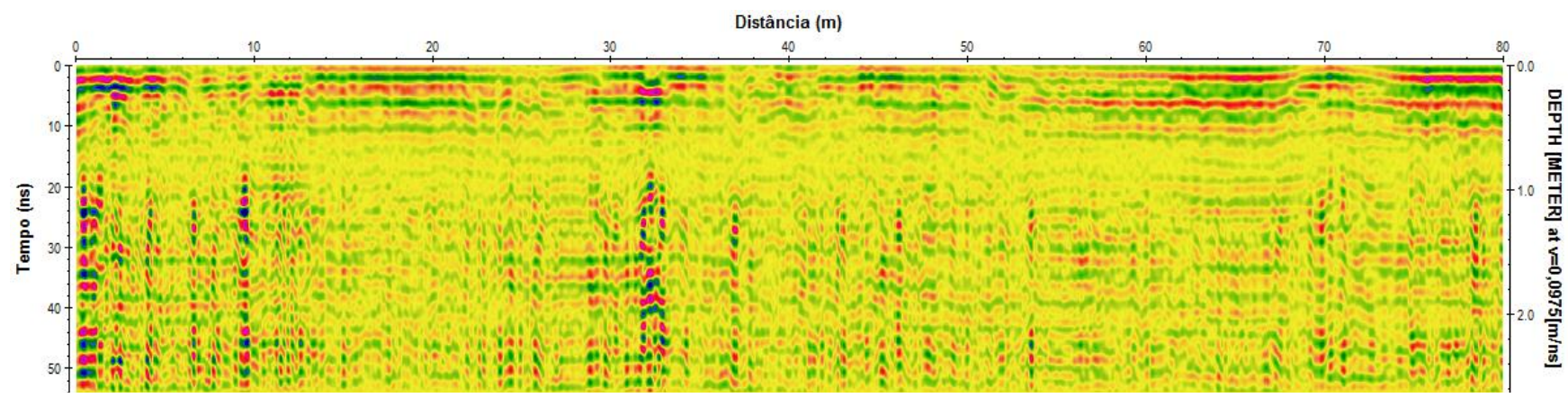

Figura 8 - Perfil 7 